\title{
10 YEARS AFTER
}

\author{
Derek Richards \\ Editor, Evidence-based Dentistry
}

Evidence-Based Dentistry (2004) 5, 87. doi:10.1038/sj.ebd.6400294

On 14 December, 10 years ago, Alan Lawrence, the founding editor of Evidence-Based Dentistry, and I organised a workshop on evidence-based dental practice at Templeton College, Oxford. We were spurred on in our activities by David Sackett, who had recently arrived in Oxford to establish the Centre for Evidence-based Medicine, and Muir Gray, who was then the Director of Research and Development at Oxfordshire Regional Health Authority and is now the Programme Director of the UK National Health Service's National Electronic Library for Health (NeLH).

The invited audience included representatives from the broad sweep of dentistry, from members of the Chief Dental Officers' Department through to general practice, including both undergraduate and postgraduate teachers. During the final general discussion period, a plan of action was generated. One of the items on that list was an evidence-based dental journal. This publication is a direct result of that meeting 10 years ago. Although not yet a decade old we are now proud to have completed our fifth volume and have achieved inclusion in Medline.

$E B D$ was seen as one element of a strategy to improve access to high-quality information for dental practitioners. The other was a Centre for Evidence-based Dentistry (CEBD), which was founded early in 1995. CEBD's main aim was to promote the teaching, learning, practice and evaluation of evidence-based dentistry. The Centre has run and been involved with numerous courses, workshops and conferences with many hundreds of dentists being introduced to the concepts and practices of evidence-based dentistry.

CEBD is one of an increasing number of organisations involved in the development of evidence-based dentistry. The Cochrane Oral Health Group (COHG) was first registered with the Cochrane Collaboration in June 1994 and, initially established in the US, is now located in Manchester Dental School here in the UK. This international group has become one of the more active Cochrane entities with 43 and 39 published reviews and protocols, respectively, with a further 16 protocols in the review stage and a further 40 or more registered titles. As we reported in $E B D,{ }^{1}$ the CEBD and COHG have joined with the Dental Health Services Research Unit and Welsh Oral Health Information Unit (WOHIU) to form the Virtual Centre for Improving Oral Health (vC-IOH). This links with other evidence-based groups such as the International Centre for Evidencebased Oral Health, which is based at the Eastman Dental Institute, in London (www.eastman.ucl.ac.uk/ pdarkins/iceph /flashindex.html). WOHIU is leading the development of the Oral Health Specialist Library for the NeLH (http://libraries. nelh.nhs.uk/oralhealth/), a developing repository of high-quality information for dental practitioners.

In the past 10 years, the profile of evidence-based dentistry has been raised enormously. Although its main focus was initially in the UK, with a small group of individuals in North America there is now a wider international perspective. There is another journal, the Journal of Evidence-Based Dental Practice, and centres for evidence-based dentistry in India and the US, and a very dynamic group in Chile (http://infodoctor.org/ obe/inicio. htm).

The American Dental Association (ADA) have been increasingly active in this area and their policy statement on evidence-based dentistry (www.ada. org/prof/resources/positions/statements/ evidencebased.asp) was a major milestone. The ADA's symposium on evidence-based dentistry, held at the association's headquarters in Chicago with a wide spectrum of representatives from general and speciality dental organisations, international dental groups, insurance companies and federal government agencies, promises to be a springboard for much further activity (www.ada.org/prof/resources/pubs/ada news/adanewsarticle.asp?articleid=1046).
In 2004, the International Association for Dental Research (IADR) approved its Evidence-based Dentistry Network, which is sponsoring a systematic reviews symposium at the IADR meeting in Baltimore in March 2005.

Although there has been much profileraising, and we have probably passed from the stage of uptake by the early adopters to the early majority, there is still much work to do. The increasing number of systematic reviews now available continues to highlight the need to improve the quality of both the conduct and reporting of dental research. This is true in many disciplines but it is still disappointing that reviews such as the Cochrane review on fissure sealants discussed in this issue ${ }^{2}$ have found that it is the quality of more recent studies that has been found wanting. This is even more unsatisfactory when you realise that clear guidelines for many study designs have been available for some time. ${ }^{3}$

A recent issue of the British Medical Journal (volume 329, no. 7430, October 2004) has also looked at the impact of the evidence-based approach over the past decade. It identifies the positive consequences of integrating the teaching of the evidence-based approach into clinical practice, bringing improved skills, attitudes and behaviour as well as knowledge. It also identifies one of the big challenges: implementation. It is all very well to have good evidence from Cochrane reviews but it is getting it into clinical practice that will bring benefits to the patients. It remains to be seen whether we can get better at this in the next 10 years.

1. Clarkson J, Pitts N, Richards D, Shaw WC, Treasure $\mathrm{ET}$, Worthington $\mathrm{H}$. Virtual centre for improving ora health - $\vee \mathrm{C}-\mathrm{IOH}$. Evid Based Dent 2004; 5:5-6.

2. Ahovuo-Saloranta A, Hiiri A, Nordblad A, Worthington H, Mäkelä M. Pit and fissure sealants for preventing dental decay in the permanent teeth of children and adolescents (Cochrane Review). In the Cochrane Library. Chichester: Wiley; 2004; issue 3.

3. Niederman R, Richards D, Matthews D, Shugars D, Worthington $\mathrm{H}$, Shaw W. International standards for clinical trial conduct and reporting. J Dent Res 2003; 82:415-416. 